\title{
Time for VAT on PPE to go the way of the Tampon Tax
}

$\mathrm{T}$ he British Dental Association has warned Rishi Sunak that failure to extend the VAT exemption for (PPE) will heap further pressures on health and social care providers already facing an uncertain future.

In an open letter to the Chancellor the Association has called for an urgent change in approach, including extension of the VAT free period, enabling health and social care providers to reclaim VAT on expenses, and even potential abolition.

The stated policy objective of the exemption was to 'relieve the burden of VAT on the price of purchasing PPE used for protection from coronavirus by front line workers.' The BDA has stressed that nothing has changed to warrant the return of normal rate.

In order to meet national guidance following the resumption of face to face services in England on 8 June, dentists are required to wear high level PPE, similar to those used in operating theatres. Industry sources have estimated costs for an aerosol generating activity - routine care involving use of high-speed instruments - at $£ 1.13$ pre-COVID-19 to $£ 11.83$ post-COVID-19, a more than ten-fold increase.

A consortium of social care providers is already pressing for a fairer set of rules to enable homes to reclaim VAT on their expenses, such as PPE, utilities, rent and repairs. The BDA has stressed this approach may also be required to assist the majority of dental practices who are likely to face significant building works to meet new public health guidance and thus increase patient numbers closer to pre-pandemic levels. It is anticipated no capital funding will be offered to meet these costs.

While NHS providers are now able to secure some PPE from the government's new PPE portal, private dentistry, which has received little to no support from the government beyond access to credit and represents over half of total public spend on dental care, remains ineligible.

British Dental Association Chair Eddie Crouch said: 'A policy designed to relieve burdens on the healthcare sector is set to go when it is most needed. The result is dentists, care homes and tens of thousands of other businesses will struggle with added costs.

'A short-term extension is essential, but we need to see real imagination from government. Giving health and social care providers the ability to reclaim these costs could offer a viable way forward.

'PPE is a fact of life for the foreseeable future. We need clarity on why VAT on this lifesaving necessity isn't going the way of the Tampon Tax.'

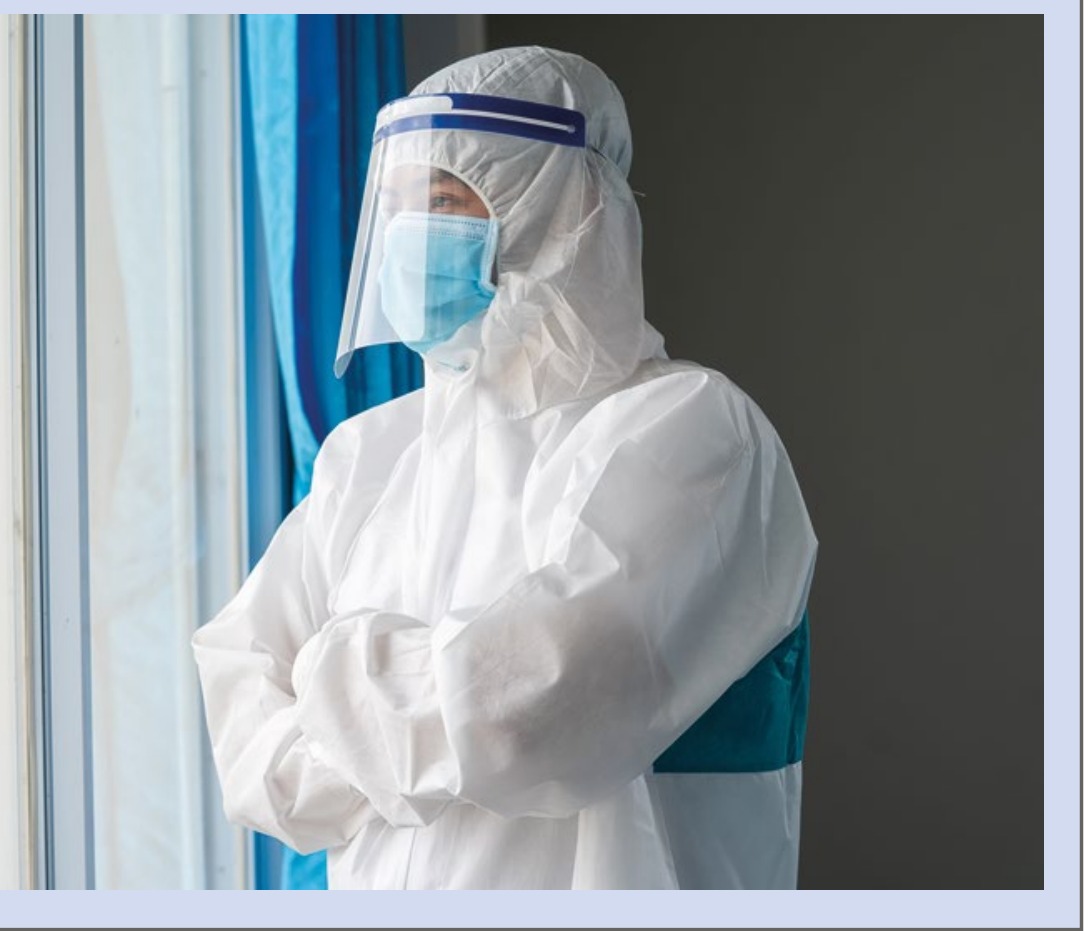

Facial surgeons support bill making it illegal to give botox or dermal fillers to under $18 \mathrm{~s}$

The British Association of Oral and Maxillofacial Surgeons (BAOMS) has welcomed the private members' bill that would make it illegal to give botox or dermal fillers to anyone under 18 for cosmetic purposes.

The Botulinum Toxin and Cosmetic Fillers (Children) Bill 2019-21, brought by Laura Trott MP as a private members' bill, had its second reading in the House of Commons.

Caroline Mills, BAOMS Lead on Facial Aesthetic/Cosmetic Surgery and Consultant Maxillofacial Surgeon at Great Ormond Street Hospital, said: 'BAOMS is pleased that Health Minister Edward Argar has given his backing to this bill, and for his department's commitment to explore increased oversight of aesthetic practitioners. We want this to be the first step towards wider regulation across the industry to protect anyone in the UK undertaking non-surgical cosmetic procedures.

'It is essential that everyone fully understands the risks they are taking when they consider a cosmetic procedure such as a dermal filler or botox and consult a fully trained medical practitioner. This is why we have consistently called for regulation in the UK to protect patients properly.

"These procedures can have significant life changing side-effects and require the competency to administer emergency medical treatment. It's recognising and managing these problems that is so important, and where patient safety maybe compromised.

'High street cosmetic procedures carry serious life-altering risks, and now is the time to implement regulation that will properly protect people in the UK?
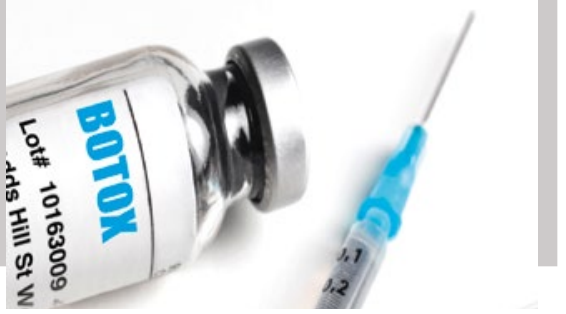